\title{
Intraventricular Hemorrhage of the Newborn without Ventricular Dilatation
}

National Cancer Institute

\section{Source}

National Cancer Institute. Intraventricular Hemorrhage of the Newborn without

Ventricular Dilatation. NCI Thesaurus. Code C99139.

Bleeding into the lateral cerebral ventricles of a newborn infant without acute ventricular dilatation. 